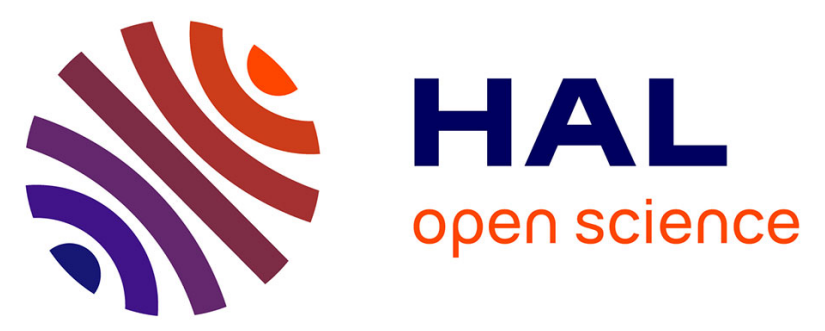

\title{
A near infrared index to assess effects of soil texture and organic carbon content on soil water content
}

Inès Soltani, Youssef Fouad, Didier Michot, Pascale Bréger, Régis Dubois, Christophe Cudennec

\section{- To cite this version:}

Inès Soltani, Youssef Fouad, Didier Michot, Pascale Bréger, Régis Dubois, et al.. A near infrared index to assess effects of soil texture and organic carbon content on soil water content. European Journal of Soil Science, 2019, 70 (1), pp.151-161. 10.1111/ejss.12725 . hal-01962148

HAL Id: hal-01962148

https://institut-agro-rennes-angers.hal.science/hal-01962148

Submitted on 8 Jan 2019

HAL is a multi-disciplinary open access archive for the deposit and dissemination of scientific research documents, whether they are published or not. The documents may come from teaching and research institutions in France or abroad, or from public or private research centers.
L'archive ouverte pluridisciplinaire HAL, est destinée au dépôt et à la diffusion de documents scientifiques de niveau recherche, publiés ou non, émanant des établissements d'enseignement et de recherche français ou étrangers, des laboratoires publics ou privés. 
A near infrared index to assess effects of soil texture and organic carbon content on soil

water content

\author{
I. Soltani, Y. Fouad, D. Michot, P. Breger, R. Dubois \& C. CudenneC \\ UMR SAS, Agrocampus Ouest, INRA 35000, Rennes, 65 rue de Saint Brieuc, France. \\ Correspondence: I. Soltani. Email: ines.soltani@agrocampus-ouest.fr
}

Running title: Effect of texture and organic carbon on soil water with NIR

\begin{abstract}
Summary
Characterization of soil hydrodynamic properties is important for assessing soil water regime. Ex situ measurements are costly and time consuming. Reflectance spectroscopy can rapidly estimate of several soil properties including soil water content (SWC). Here, we evaluated the ability of visible (vis) and near-infrared (NIR) spectroscopy to assess the effects of soil texture and soil organic carbon (SOC) content on SWC. Thirteen undisturbed soil surface blocks were sampled in 2014 across the Brittany region, western France. Textural classes ranged from sandy loam to sandy clay loam texture, and SOC content ranged from $8.12 \mathrm{~g} \mathrm{~kg}^{-1}$ to $62.3 \mathrm{~g} \mathrm{~kg}^{-1}$. Aggregates of 3-4-cm width and 5-6-cm height were extracted and set at 10 matric potentials from saturation to permanent wilting point $(1585 \mathrm{kPa})$. At given pressure heads, soil samples were scanned in triplicate to acquire reflectance spectra between 350 and $2500 \mathrm{~nm}$. Spectra were converted into continuum removal and we focused on the absorption band near $1920 \mathrm{~nm}$, which is linked to combination vibrations of water. We defined a new index based on the full width at half maximum (FWHM) of the absorption feature near 1920 nm. Results showed a linear relation between this NIR index and the volumetric SWC $\left(R^{2}>0.9\right)$ for every soil aggregate. The slope and the intercept of the line were well correlated with soil texture and SOC content. Results indicated that the parameters of this linear relation
\end{abstract}


offer a new way to study SWC and water retention properties of soils in relation to their physical properties.

Keywords: Soil water spectral index, vis-NIR spectroscopy, continuum removal, water retention, soil hydrodynamic properties, soil moisture. 


\section{Highlights}

- We used vis-NIR spectroscopy to assess effects of texture and SOC content on soil water content SWC.

- Formulated a new spectral index based on absorption feature of water near $1920 \mathrm{~nm}$.

- Linear relation between SWC and NIR index; its parameters are related to texture and SOC content.

- Vis-NIR spectroscopy can be relevant to assess effects of texture and SOC content on SWC. 


\section{Introduction}

Soil water content (SWC) is one of the major hydrodynamic soil properties that govern soil functioning in agroecosystems and greatly affects soil management. It is also the key factor across a range of environmental processes including successful plant growth and productivity, erosion, pedogenesis, soil biogeochemistry and water regime, particularly in unsaturated soils. To understand and model these processes, the monitoring of soil hydrodynamic properties over large areas is highly desirable.

The conventional methods to measure SWC by oven drying soil samples collected from agricultural fields are destructive, costly and time-consuming (Romano \& Palladino, 2002). A rapid, non-destructive and cost-effective alternative method to determine SWC, with acceptable precision, is needed to allow farmers and land managers to make rational use of water resources, and for the assessment and management of soil quality.

Pedotransfer functions (PTFs) and physico-empirical models have been used for this purpose, relying on more readily available and less expensive soil analytical data (Pachepsky \& Rawls, 2003; Patil \& Singh, 2016). These functions are based on relations identified between SWC and other soil properties such as soil texture, clay, sand and organic matter (OM) contents, and bulk density (Patil \& Singh, 2016). However, PTFs are still inaccurate for predicting some of the hydrodynamic soil properties. They may also require analytical data to calibrate a predictive model.

Over the last decades, diffuse reflectance spectroscopy (DRS) techniques have been used increasingly. Methods based on DRS offer several advantages compared to conventional ones because they are rapid, cost-effective and non-destructive. Therefore, the spread within the soil science community of soil spectroscopy in the visible (vis), near (NIR) and mid-infrared (MIR) spectral ranges enabled various physical, chemical and biological soil properties to be assessed (Stenberg et al., 2010; Genot et al., 2014), especially SWC (Bowers \& Hanks, 1965; 
Lobell \& Asner, 2002), SOC content, cationic exchange capacity (CEC), clay, silt and sand contents, and pH (Ben Dor et al., 2003; Minasny et al., 2008; Rodionov et al., 2014). Furthermore, investigating the spectral characteristics of soil samples showed correlations between soil spectra, SOC content and SWC. Overall, several studies have shown that soil reflectance in the vis-NIR decreases with OM (Rodionov et al., 2014) and SWC (Lobell \& Asner, 2002; Whiting et al., 2004).

The vis-NIR spectroscopy studies of SWC have been investigated for three main purposes: (i) variation in laboratory (Bowers \& Hanks, 1965; Lobell \& Asner, 2002) and field (Kaleita et al., 2005) observations of reflectance spectra with SWC, (ii) prediction of SWC using either the entire spectrum (Mouazen et al., 2006; Janik et al., 2007) or some absorption bands (Whiting et al., 2004; Zhu et al., 2010) and (iii) the effect of moisture on the quality of prediction of some soil properties (Stenberg, 2010; Rodionov et al., 2014). However, vis-NIR spectroscopy has rarely been used to assess the effects of texture and SOC content on SWC and ultimately soil water retention (SWR). Janik et al. (2007) predicted SWC for a large variety of surface soils from southern Australia at a range of matric suctions from 1 to 1500 kPa by MIR spectroscopy and partial least squares (PLS) regression. They concluded that the MIR PLS prediction method performed at least as well as some PTFs. McBratney et al. (2006) used reflectance spectra of soils to predict various soil properties (clay, silt, sand, OC, CEC, pH) by PLS regression that were in turn used in an inference system to predict other important and functional soil properties with PTFs (bulk density and available water capacity). Santra et al. (2009) and Babaeian et al. (2015) evaluated PTF approaches to use spectral reflectance over the vis-NIR region $(350-2500 \mathrm{~nm})$ for predicting SWR curves in the place of basic soil properties. They showed that these new transfer functions, called spectrotransfer functions (STFs), have similar accuracy to those of PTFs for estimating hydrodynamic properties. They further developed point and parametric transfer functions 
based on the van Genuchten soil hydraulic model (VG). More precisely, they developed STFs that related VG hydraulic parameters to spectral reflectance values. They also derived point transfer functions that estimated either hydraulic conductivity (Ks) (Santra et al., 2009) or SWC at specific matric potentials (Babaeian et al., 2015).

This study aimed to validate the hypothesis that soil reflectance, and more specifically the absorption feature of water near $1920 \mathrm{~nm}$, can be used to evaluate the effect of texture and SOC content on SWC and SWR. For this purpose, we defined a new spectral index based on the absorption band near $1920 \mathrm{~nm}$ and we established its relation to volumetric SWC of various topsoils from Brittany (western France) at different pressure heads from saturation to permanent wilting point.

\section{Materials and methods}

\section{Soil dataset}

The study area is in the Armorican Massif in Brittany (Figure 1), western France which is characterized by a heterogeneous landscape with different soil textures, SOC contents and soil parent materials. Soil data come from the the latest 2014-2015 soil survey (228 horizons from 64 soil profiles) of the -Solsle Bretagne" project across the whole Brittany (Bretagne) region, representing a large diversity of soil conditions (see www.sols-de-bretagne.fr for more detail and online digital maps). The rationale of this survey was as follows. In each observed horizon, a sample was collected for analysis of physicochemical properties as well as an undisturbed block of soil for soil water retention properties and spectral measurements. The particle-size distribution was measured by the Robinson pipette method according to the NF X31-107 certified method (AFNOR, 2003) and five classes were determined: clay $(0-2 \mu \mathrm{m})$, fine silt $(2-20 \mu \mathrm{m})$, coarse silt $(20-50 \mu \mathrm{m})$, fine sand (50-200 $\mu \mathrm{m})$ and coarse sand (200-2000 $\mu \mathrm{m})$. The SOC content was measured by dry combustion with a $\mathrm{CHN}$ analyser (Thermo Finnigan EA 1112, Milan, Italia) according to the NF ISO 10694 certified method (AFNOR, 
1995). Undisturbed soil blocks were stored in a cold room at $4^{\circ} \mathrm{C}$ until required for physical and spectral measurements.

For this study, we selected 13 organo-mineral A horizons out of 59 A horizons using conditioned Latin hypercube sampling (cLHS). This method is a stratified random procedure that provides an efficient way of sampling variables from their multivariate distributions (Minasny \& McBratney, 2006). The cLHS enables organo-mineral A horizons to be selected with a good representation of the regional soil diversity according to environmental covariates. For covariates, we used soil parent material, textural class using the French GEPPA (_Groupe d'Etude pour les Problèmes de Pédologie Appliquée‘) 17-class texture triangle (1963), the SOC content and the fine silt/coarse silt ratio. The GEPPA textural triangle for the soil samples selected is shown in Figure 2.

\section{The SWC measurements at different pressure heads}

In the laboratory, each block of soil was broken down at the field moist state into aggregates of approximately 3-4-cm width and 5-6-cm length. Four aggregates were collected in quadruplicate for measurements, thus enabling us to obtain 52 aggregates. Once saturated with deionized water, all aggegrates were first placed on suction table apparatus and then in a pressure cell to be dried gradually. Aggregates were brought successively to pressure heads of -1 and $-3.2 \mathrm{kPa}$ (corresponding to $\mathrm{pF} 1$ and 1.5 , respectively) on the suction table apparatus. Then, they were brought to pressure heads of $-10,-20,-31.6,-63,-100,-316,-1000$ and $1585 \mathrm{kPa}$ (corresponding to $\mathrm{pF} 2,2.3,2.5,2.8,3,3.5,4$ and 4.2 , respectively) using a pressure cell following the ISO 11274 standard (AFNOR, 1998). At each pressure head, the wet weight of soil aggregates was taken. Finally, the aggregates were oven-dried at $105^{\circ} \mathrm{C}$ during 48 hours and their dry mass was then weighed to determine their gravimetric SWC at the different matric potentials. The dry bulk density (BD) was measured for the whole aggregates by the kerosene displacement method (Abrol \& Palta, 1968), according to X31- 
505 standard (AFNOR, 1992). For each soil aggregate, the gravimetric SWC was then converted to volumetric SWC and we calculated the total porosity by considering a particle density of $2.65 \mathrm{~g} \mathrm{~cm}^{-3}$. The SWC, BD and total porosity of the four aggregates were averaged at different pressure heads.

\section{Spectral scanning and spectral treatments}

Once the desired water pressure head was reached and after soil aggregates had been oven dried, reflectance spectra of soil samples were recorded with a full range vis-NIR spectrometer (ASD Fieldspec ${ }^{\circledR}$ 3, Analytical Spectral Devices Inc, Boulder, CO, USA) from 350 to $2500 \mathrm{~nm}$ wavelength with a sampling interval of $1 \mathrm{~nm}$. The ASD spectrometer was used in a bare fibre optic configuration with a $25^{\circ}$ view angle. All spectra were recorded using a standard contact probe that embeds both an optical fibre and a halogen bulb light source with a colour temperature of approximately $2901 \mathrm{~K}$. This reduces errors associated with stray light during measurement and atmospheric water content. Before spectral acquisition of each soil sample, the ASD spectrometer was optimized on a dark current followed by white reference panel (Spectralon ${ }^{\circledR}$ ). Spectral measurements were taken in the laboratory in a dark room. At given pressure heads and for each soil aggregate, reflectance spectra were acquired in triplicate by slightly modifying the position of the contact probe. As a result, the single spectrum for a given soil aggregate was an average of 30 scans and the final spectrum used in the treatment was an average of the three replicates. The total time for recording the spectra was standardized to $6 \mathrm{~s}$ per aggregate to avoid heating and drying of thesamples. To exclude noisy ranges of vis-NIR spectra, the spectral interval was narrowed to 400 to $2500 \mathrm{~nm}$. Each spectrum was corrected with a splice correction and the continuum removal (CR) technique (Clark \& Roush, 1984) was applied to all spectral data. It was applied to ease interpretation of the absorption features in a diffuse reflectance spectrum by normalizing spectra to a common base line. 
A new soil water spectral index (SWSI)

Soil is a heterogeneous mixture of various constituents, therefore, a unique spectral response for soil properties is by no means certain (Chang et al., 2001). One method of evaluating the spectral response for a soil property is to study the relation between wavelength and the value of the soil property. The strong change in both water absorption features near 1440 and 1920 $\mathrm{nm}$ suggests they could support an effective indicator for characterizing SWC. Moreover, the depth of the absorption band near $1920 \mathrm{~nm}$ is deeper and changes over a wider range of magnitude than the one near $1440 \mathrm{~nm}$, which suggests that the $1920 \mathrm{~nm}$ absorption feature is more sensitive to changing water content. Therefore, we focused on this water absorption feature near $1920 \mathrm{~nm}$ to define a new NIR spectral index that will be related to soil water status with drying. More precisely, at a given pressure head we measured the full width at half maximum (FWHM) of the $1920 \mathrm{~nm}$ absorption band, i.e. the width at half of the height of the feature. We defined the new index, which we called soil water spectral index (SWSI), as follows:

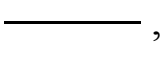

where $\mathrm{SWSI}_{i}$ is the soil water spectral index at the $i$ th value of pressure head, $\mathrm{FWHM}_{i}$ is the full width at half maximum at the $i$ th pressure head and $\mathrm{FWHM}_{\text {sat }}$ is the full width at half maximum at saturation. The index is a function of the normalized FWHM and characterizes soil dryness because it is 0 at saturation and increases towards 1 with drying.

\section{Statistical analyses}

Statistical analyses were conducted using the $\mathrm{R}$ (v. 3.5.0) statistical programming environment. Least squares regression was carried out for each soil sample to establish the regressions relating SWC to SWSI for the ten pressure heads considered, and the assumptions of linear regression were checked. The Pearson correlation matrix was calculated to explore 
the correlations between soil properties (SOC, texture and BD) and two parameters obtained from the relation between SWC and SWSI. Prior to Pearson correlation analysis, the statistical distribution was examined for these variables. Furthermore, we defined three classes of SOC content and within each class, soil samples were split into two texture classes which enabled six groups to be identified from our dataset. We did an analysis of variance (ANOVA) to assess whether the mean values of the two parameters of the SWC-SWSI relations were different between groups at $P=0.05$. Prior to ANOVA, the assumptions of equality of variances and normality were checked with the Bartlett and Shapiro-Wilk tests, respectively. The independence of data was verified because for a given soil variable, its value for each soil was independent of those of other soils. The Fisher's least significant difference (LSD) test was carried out to check which SOC and texture groups were significantly different.

\section{Results and discussion}

\section{Soil properties}

The physicochemical properties of the soil samples are provided in Table 1. Soil samples display a wide range of soil textural classes from sandy loam to sandy clay loam textures (Figure 2) and of SOC contents from 8.12 to $62.30 \mathrm{~g} \mathrm{~kg}^{-1}$, which were consistent with the typical textures and SOC contents observed across Brittany. Clay content was small for most soil samples (clay $<30 \%$ ), silt content had a wide range $(28-76 \%)$ and sand content ranged between 9 and $58 \%$. Bulk density of the clods for all soil samples ranged between 0.92 and $1.73 \mathrm{~g} \mathrm{~cm}^{-3}$.

Variation in soil spectral reflectance with soil texture and SOC content.

The vis-NIR diffuse reflectance spectrum of soil is the result of interactions between the incident electromagnetic radiation and soil chemical and physical characteristics. Soil chemical elements such as organic and mineral compounds, as well as the adsorbed and 
interstitial soil water, absorb a fraction of the incident light at specific wavelengths (Viscarra Rossel \& Behrens, 2010). The soil particle size and resulting surface roughness are also factors that strongly influence the soil spectral response in vis-NIR (Sadeghi et al., 2018). In general, a decrease in particle size leads to an increase in scattering and so to an increase in soil reflectance. Thus, different soil textures have different shapes of spectra.

Three soil samples were selected from our dataset to illustrate the specific change in reflectance spectra as affected by texture and SOC content (Figure 3). The sample A3 was a coarse-textured soil and the other two (A9 and A10) were fine-textured. According to the GEPPA 17-class texture triangle (Figure 2), A3 is identified as Ls (i.e. Loamy sand), A9 and A10 are both identified as LAS (i.e. Sandy clay loam). Each spectrum in Figure 3 is an average of the four replicated scanned spectra of soil aggregates after they had been oven dried. The samples A3 and A10 have large SOC contents, but with a small difference, 48.65 and $50.85 \mathrm{~g} \mathrm{~kg}^{-1}$, respectively, whereas A9 had a smaller SOC content (19.68 $\left.\mathrm{g} \mathrm{kg}^{-1}\right)$. Figure 3 shows that the overall reflectance increases with the increase in fineness of soil texture because of the dominance of clay particles in the soil. Previous researchers (Ben Dor et al., 2003; Stenberg, 2010) who showed that reflectance in the vis-NIR spectral range increases when clay content increases also reported this known global tendency. According to Genot et al. (2014), the effect of particle size on the spectrum of reflected light intensity is inversely proportional to the particle diameter. Sandy soils with the largest diameters absorb more light than those with medium and fine particles. This can be explained by the optical properties of different soil types. In theory, scattering at the surface allows light to change its direction of propagation and it is the passage through the various materials that causes the absorption. There is a mean optical path length, which can be used to describe the absorption process (Clark \& Roush, 1984). Increasing the length of a mean optical path leads to an increase in the probability of absorption and consequently to a decrease in reflectance. Both Nolet et al. 
(2014) and Janik et al. (2016) associated the increase in particle size of soils such as coarse soils with an increase in the mean optical path length, and so the decrease in reflectance. Nevertheless, a decrease in reflectance with the increase in soil fineness was also observed by other authors (Santra et al., 2009) .

The soil samples, A9 and A10 that were selected from the same textural class (LAS) with similar sand:clay ratios (Table 2) differ significantly in their SOC content, 19.68 and $50.85 \mathrm{~g}$ $\mathrm{kg}^{-1}$, respectively. Figure 3 shows that for similar soil textures, reflectance intensity is inversely related to SOC content. A decrease in reflectance spectra with the increase in SOC content has been reported in numerous studies (Chang et al., 2001; Rodionov et al., 2014).

\section{Variation in soil spectral reflectance with SWC}

The effect of moisture on soil NIR reflectance spectra has been documented in several previous publications. As expected, our results showed that the reflectance intensity of all soil samples decreased as SWC increased, which accorded largely with the reported behaviour in the literature (Lobell \& Asner, 2002; Zhu et al., 2010). Moreover, soil reflectance decreased systematically, but not proportionally, with increasing matric potential (Knadel et al., 2014). Figure 4(a) shows an example with the reflectance curves for the sample A11 at different moisture levels, from saturated to the oven-dried state. The largest reflectance was obtained for the oven-dry sample at $105^{\circ} \mathrm{C}$, and conversely the smallest reflectance curve was obtained for the wettest state. Moreover, increasing SWC affected the shape of spectra because of the occurrence of well-defined water absorption bands near wavelengths of 1440 and $1920 \mathrm{~nm}$. Zhu et al. (2010) located these absorption features at 1450 and $1940 \mathrm{~nm}$ whereas Demattê et al. (2006) identified them at 1400 and $1900 \mathrm{~nm}$. These absorption features were emphasized more with the use of the continuum removal, Figure 4(b). The feature near $1440 \mathrm{~nm}$ is related to the hydroxyl functional group $\mathrm{O}-\mathrm{H}$ and water molecule vibration, and the feature near 1920 
$\mathrm{nm}$ is linked to water molecules themselves (Clark, 1999). The water tends to widen and lengthen these two absorption features.

The absorption band near $2200 \mathrm{~nm}$ results from the vibrations of hydroxyl ions associated with clay minerals and structural water integrated into the crystalline structure of clay minerals (Ben Dor et al., 2003). In contrast to the bands near 1440 and $1920 \mathrm{~nm}$, the amount of water does not noticeably affect the magnitude of that band. However, when the absorption band near $1920 \mathrm{~nm}$ becomes stronger, it partly or completely overlaps the band near $2200 \mathrm{~nm}$, depending on clay content and mineral types (Demattê et al., 2006). The absorption feature in the visible range of spectrum $[400,700 \mathrm{~nm}]$ is due to electronic transitions in the iron oxides. The effect of water in this spectral range is weak and is associated with colour because soil darkness changes with variable water content. Furthermore, Figure 4 also shows that the depth of the absorption band near $1920 \mathrm{~nm}$ is deeper and changes over a wider range of magnitude than the depth of the $1440 \mathrm{~nm}$ band, which means the $1920 \mathrm{~nm}$ absorption feature is more sensitive to changing water content. Some authors (Bowers \& Hanks, 1965; Stenberg et al., 2010; Zhu et al., 2010) have found this band to be better for estimating the SWC than the band near $1440 \mathrm{~nm}$. For example, some authors found a decreasing exponential relation between SWC and the CR at $2200 \mathrm{~nm}$ (Lobell \& Asner, 2002). However, other authors estimated soil moisture by a multiple linear regression model based on the area of the absorption features near 1400, 1900 and $2200 \mathrm{~nm}$ (Demattê et al., 2006). The partial least squares (PLS) regression was also used to predict SWC from the reflectance taken over the entire vis-NIR electromagnetic spectrum (Kaleita et al., 2005; Mouazen et al., 2006; Kim et al., 2014). Now, focusing on the more specific feature of water absorption $1920 \mathrm{~nm}$, Figure 4(c) shows that the observed broadening can be characterized by the full FWHM of the band. The strong change in FWHM with drying suggests that it will be an effective indicator for characterizing SWC,therefore we expect a relation between FWHM and SWC. 


\section{The SWC versus SWSI}

In addition to observed changes in reflectance, we considered the effect of SWC on FWHM of the absorption feature near $1920 \mathrm{~nm}$. The result of continuum removal shows an increase in FWHM with an increase in SWC (Figure 4c) and FWHM appears to be correlated with SWC. The relations between SWC and SWSI are summarized in Table 2 for the thirteen topsoil samples, and six of these are presented in full in Figure 5. The SWSI shows a significant linear relation with the measured SWC, as illustrated by the six selected soil samples, taking into account variation in texture and SOC content. Figure 5 shows that SWC decreases linearly as the index SWSI increases.

Table 2 indicates that for all the samples the coefficient of determination $R^{2}$ is equal to or larger than 0.95 . The $R^{2}$ values ranged from $95 \%$ for soil sample A2 to $99 \%$ for A13. Linear regression was highly significant for all soil samples with $P<<10^{-5}$. Slopes of the regression lines ranged from -1.345 (A8) to -1.144 (A12). Rather than slope in the following sections, we used its absolute value which we denoted AvS. The AvS parameter is such that for a variation of a unit in SWSI it gives the variation in SWC during drying. The smaller is the AvS value, the smaller is the variation in SWC and the associated amount of water released. Accordingly, AvS is directly related to SWR. Intercepts ranged from $0.521 \mathrm{~m}^{3} \mathrm{~m}^{-3}$ (A2) to $0.663 \mathrm{~m}^{3} \mathrm{~m}^{-3}$ (A13). The intercept was obtained when SWSI equalled zero, which was at saturation for FWHM and corresponded to the theoretical value of SWC at saturation.

Figure 5 and Table 2 show clearly that the linear relation between SWC and the new spectral index SWSI is texture-dependent. Indeed, the intercept that represents the volumetric SWC at saturation is mainly influenced by soil texture. The largest values of intercept were observed for fine-textured soils from A10 to A13 and the smallest values were for coarse-textured soils A1, A2, A4 and A5 (Table 2). The SOC content also has an effect on the intercept. Regarding the coarse-textured soil, the effect was more pronounced for soil sample A3. For this sample 
the sand:clay ratio was 7 , but SOC content was very large $\left(48.65 \mathrm{~g} \mathrm{~kg}^{-1}\right)$, which presumably explained the very small BD of $0.98 \mathrm{~g} \mathrm{~cm}^{-3}$ (i.e. large total porosity), and thus the large intercept value. For the fine-textured soils, two trends stood out and were linked to the sand:clay ratio. For soil samples A9, A10 and A11, the ratio was at least 1:1 and increasing SOC content significantly increased the intercept. However, for the soil samples A12 and A13 with ratios of $6: 10$ and 7:10 respectively, there was no effect on the intercept with increasing SOC content. The large value of the intercept was then mainly due to the texture, and more precisely to clay content. Otherwise, the intercept, that is SWC at saturation, can also refer to water holding capacity (WHC) and is greatly controlled by soil texture, mainly clay content, and SOC content. In fact, soils with smaller particles (silt and clay) have a larger surface area than those with larger sand particles, and a large surface area enabls a soil to hold more water. In other words, soils with large silt and clay contents have a larger WHC and intercept. The SOC content also affects WHC because of the affinity that organic matter has for water. Thus, as SOC content increased, the WHC increased and intercept increased.

The slope ofthe linear relation between SWSI and SWC is related to the SWR of a given soil because it corresponds to the variation in the rate of water released, i.e. the variation in SWC for a unit variation in SWSI. Therefore, decreasing the slope leads to a greater SWR and less available water. Overall, our results accord with the widely known effects of texture and SOC content on SWR properties (Saxton et al., 1986; Rawls et al., 2003; Bronick \& Lal, 2005). The fine-textured soils A12 and A13 had a small slope. These samples were characterized by the small BD (i.e. large total porosity) of 1.06 and $1.09 \mathrm{~g} \mathrm{~cm}^{-3}$, respectively. In general, more pore space could lead to greater SWR, although the pore-size distribution and SOC content also have an effect on this property. In the LAS textural class with a sand:clay ratio of $1: 1$, SOC content appeared to be an influencing factor because the slope increased with SOC content. It is known to improve aggregation and aeration of soils and thus their SWR. 
Thus, it appears from our results that both slope, which gives SWR, and intercept, which is SWC at saturation, are related to soil texture and more precisely to the sand:clay ratio and to SOC content.

\section{Correlation between soil physical properties and parameters of the linear relation}

Different textures give rise to different pore sizes in the soil. When only one size of particle is involved, the pore size is proportional to the particle size (Dexter, 2004). However, when a mixture of particle sizes is present, as is usual in soils, the situation is more complicated.

Table 3 gives the Pearson correlation matrix for the parameters of the SWSI-SWC relation (AvS and intercept) and soil physical and chemical properties (BD, clay, silt, sand and SOC contents). Overall, the results are in accord with observations made above (Figure 5 and Table 2). The intercept was correlated at $P$ of 0.001 to soil physical properties. It was negatively correlated to BD $(r=-0.75)$ and sand content $(r=0.44)$, whereas it was positively correlated to silt content $(r=0.36)$. Our results did not show any significant correlation between the intercept and clay content. The correlation was also significant and positive between the intercept and SOC content $(r=0.5)$. The AvS was significantly correlated to the intercept, BD and clay content, but with different levels of significance, $P$-values of $0.001,0.01$ and 0.05 respectively (Table 3). Our results did not show any significant correlation between AvS with silt, sand or SOC contents.

The correlation matrix (Table 3) also shows that the effects of SOC, clay, silt and sand contents on AvS are opposite to those observed with the intercept. When clay content had a significant correlation with AvS, the effect of SOC content was not significant, and when sand and silt contents were significantly correlated with the intercept the effect of SOC content was highly significant. The non-significant effect of SOC content with a significant effect of clay content and vice versa suggests that the effect of SOC content is indirectly 
correlated to soil texture and that the relation of soil water retention to SOC content is affected by proportions of the textural components, in particular clay content.

A new approach for comparing hydrodynamic properties of soils.

Our results above suggested that the two parameters AvS and intercept of the linear relation between SWSI and SWC were relevant to study hydrodynamic soil properties such as SWR and WHC. We propose a way to explore and compare these properties within our dataset in the plane based on the intercept and AvS. To emphasize our results, we defined three classes of SOC content $\left(\mathrm{SOC} \leq 20,20<\mathrm{SOC} \leq 30\right.$ and $\left.\mathrm{SOC}>30 \mathrm{~g} \mathrm{~kg}^{-1}\right)$, and within each class the soil samples were split into coarse and fine-textured soil. Six groups (G1 to G6) were defined as shown in Table 4; odd groups were identified as coarse-textured and even groups as finetextured soils. For each group, the average values of intercept and AvS were calculated (Table 4). Moreover, the results of ANOVA for both intercept and AvS showed (Table 5) that SOC and texture had separately a significant effect on the intercept only, with $P<0.05$, and there was no interaction between them. The pairwise comparison of the mean values of the intercept of the three classes of SOC content, carried out with the Fisher's LSD test, showed that a significant difference was obtained only between the class of SOC with the larger contents $\left(\mathrm{SOC}>30 \mathrm{~g} \mathrm{~kg}^{-1}\right.$ ) and the two other classes of SOC content $(\mathrm{SOC} \leq 20$ and $20<\mathrm{SOC}$ $\leq 30 \mathrm{~g} \mathrm{~kg}^{-1}$ ). For the two textural classes, Fisher's LSD test showed that the mean value of the intercept was significantly different between the coarse- and fine-textured soils.

Figure 6 shows the distribution of the six groups in the plane of the intercept and AvS. At first glance, Figure 6 shows that the distribution of groups in this plane is related to both texture and SOC content and enables two clusters to be identified from the soil groups. Cluster 1, for the intercept, ranged between ]0.5, 0.6[ and AvS ranged between ]1.2, 1.3[, whereas for cluster 2 the respective ranges were ]0.6, $0.7[$ and $] 1.35,1.45[$. In cluster 1 , moving from G1 to $\mathrm{G} 2$, that is from coarse to fine texture, brought out the textural effect, whereas moving from 
G1 to G3 showed the effect of increasing SOC content. In the first case, the fine-textured soils of G2 had on average a larger intercept and a smaller AvS indicating larger WHC and SWR than for the coarse-textured soil of G1. In the second case, both G1 and G3 were identified as coarse-textured soils but with larger SOC content for G3; the position in the plane was in accord with the positive effect of SOC content on SWR and the increase in SWC at saturation and thus the intercept. Some similar observations can be made in cluster 2 . The relative position of the coarse-textured group G5 compared to the fine-textured group G6, given that SOC content was similar and everything else remained the same, emphasized the effect of soil texture. Consequently, soils of G6 had on average a larger intercept and smaller AvS, i.e. a greater SWR. However, the relative positions of both fine-textured groups G4 and G6 were probably from the effect of increasing SOC content. In this case, the increase in SOC content improved WHC, and therefore the intercept. Further, the well-known effect of SOC content is the improvement in aggregation and soil structure, which affects pore-space distribution, therefore the creation of macropores in fine-textured soils could explain the increase in AvS. In general, WHC of coarse-textured soils was much more sensitive to the amount of SOC than fine-textured soils. In fine-textured soils, the effect of increasing SOC content on WHC or the intercept was much more significant when SOC content was increased slightly from 0 to $30 \mathrm{~g}$ $\mathrm{kg}^{-1}$ and became less sensitive with increasing SOC content of more than $30 \mathrm{~g} \mathrm{~kg}^{-1}$. This trend accords with the ones reported by Rawls et al. (2003) and Minasny \& McBratney (2018) who observed that the sensitivity of WHC water holding capacity to changes in SOC content decreased as the clay content increased.

\section{Intercept and $A v S$ as a quality index of soil structure}

Figure 6 also shows that the sensitivity of AvS to increasing SOC content depends on textural composition. A small increase in SOC content leads to a decrease in AvS in coarse soils and to an increase in AvS in fine-textured soils. A large increase in SOC content resulted in an 
increase in AvS for the two soil textures. In general, increased organic matter in soil influences soil aggregation and pore-space distribution, and the effects of SOC content are similar to those of clay content. Pore-size distribution is also affected by SOC content. Both macro- and micro-porosity might increase with an increase in SOC content (Rawls et al., 2003). In coarse-textured soils, the increase in number of small pores is primarily the result of an increase in SOC content. The increase in microporosity leads to an increase in the SWR force and the release of water becomes more difficult. Therefore, it can explain the decrease in AvS, which might provide an estimate for the rate of release of water. The large SOC content of more than $30 \mathrm{~g} \mathrm{~kg}^{-1}$ for the coarse-textured soil (G5) probably improved aggregation and the increase in macropores, therefore, increasing AvS. In fine-textured soils, any increase in SOC content resulted in an increase in the number of macropores, which improved inter-pore connection. Consequently, soil releases water more rapidly, which might explain the increase in AvS. The effect of organic carbon on AvS was more significant with a small increase in SOC content in fine-textured.

The comparison of average intercepts with AvS (Figure 6) revealed a new plane that could be relevant to study the effects of texture and SOC content on soil hydrodynamic properties and soil physical quality. Two soil groups can be observed in Figure 6. The first group (G1, G2 and G3) is marked by a small WHC (intercept $<0.6 \mathrm{~m}^{3} \mathrm{~m}^{-3}$ ) and a small rate of release of water $(\mathrm{AvS}<1.3)$. It is composed of fine-textured soils with small $\mathrm{SOC}$ content $(\mathrm{SOC} \leq 20 \mathrm{~g}$ $\mathrm{kg}^{-1}$ ) and coarse-textured soils with small and medium SOC contents ( $\mathrm{SOC}<30 \mathrm{~g} \mathrm{~kg}^{-1}$ ) that can define poor soil structure (Cluster 1). The second group (G4, G5 and G6) is composed of coarse soil samples with large SOC content (SOC $>30 \mathrm{~g} \mathrm{~kg}^{-1}$ ) and fine-textured soils with medium and high SOC contents ( $\mathrm{SOC}>20 \mathrm{~g} \mathrm{~kg}^{-1}$ ). The second group possibly defines a good soil structure (Cluster 2) with the large WHC (intercept $>0.6 \mathrm{~m}^{3} \mathrm{~m}^{-3}$ ) and ease of water release $(\mathrm{AvS}>1.3)$. Therefore, with an increase in intercept with soil microposorsity resulting 
from clay content in fine-textured soils and from SOC content in coarse-textured soils, AvS increases with macroporosity that can result from SOC content in fine-textured soils and sand content in coarse soils.

\section{Conclusion}

For the samples studied, SWSI showed a linear relation with volumetric SWC. Furthermore, the slope and intercept of the linear relation varied with different soil types and they correlated significantly with texture and SOC content. The intercept can be used to estimate SWC at saturation, and as such it was significantly correlated to soil BD, SOC content, and sand and silt contents. Overall, it increased when soil porosity increased (i.e. BD decreased), which was principally related to soil particle-size distribution. In coarse soils, microporosity might increase with increasing SOC content leading to an increase in the intercept and decrease in AvS. In fine-textured soil, an increase in SOC content resulted in an increase in macroporisity, and therefore AvS increased. Thus, the effects of SOC content on both intercept and AvS changed with soil texture, and especially the sand:clay ratio. Furthermore, our results enabled us to define a new approach based on the plane, i.e. the intercept and AvS, that can be used to study soil hydrodynamic properties such as SWR and WHC, and monitor the effects of some key factors of soil such as texture and SOC content on SWC. Our results also showed that NIR spectroscopy was relevant for assessing structure and soil physical quality, which opens up further possibilities. In addition, an increase in the intercept and AvS was generally associated with an improvement in soil structure. 


\section{Acknowledgements}

This research was performed in the framework of the - Sol de Bretagne 2" programme that is supported financially by the Regional Council of Brittany and Agrocampus Ouest. The authors gratefully acknowledge all the soil surveyors who participated in soil sample collection, and the IPs B. Lemercier and C. Walter. The first author is supported by a PhD grant allocated by the Tunisian State. 


\section{References}

Abrol, I.P. \& Palta, J.P. 1968. Bulk density determination of soil clods using rubber solution as a coating material. Soil Science, 106, 465-468.

AFNOR. 1992. Norme X31-505. Qualité des sols-Méthodes physiques-Méthode de détermination du volume apparent et du contenu en eau des mottes. Association Française de Normalisation, Paris-La défense.

AFNOR. 1995. NF ISO 10694. Qualité du sol-Dosage du carbone organique et du carbone total après combustion sèche (analyse élémentaire). Association Française de Normalisation, Paris-La défense.

AFNOR. 1998. Norme NF ISO 11274. Qualité du sol—Détermination de la caractéristique de la rétention en eau-Méthodes de laboratoire. Association Française de Normalisation, ParisLa défense.

AFNOR. 2003. Norme NF X31-107. Qualité du sol-Détermination de la distribution granulométrique des particules du sol-Méthode à la pipette. Association Française de Normalisation, Paris-La défense.

Babaeian, E., Homaee, M., Vereecken, H., Montzka, C., Norouzi, A.A. \& van Genuchten, M.T. 2015. A Comparative study of multiple approaches for predicting the soil-water retention curve: hyperspectral information vs. basic soil properties. Soil Science Society of America Journal, 79, 1043-1058.

Ben Dor, E., Goldlshleger, N., Benyamini, Y., Agassi, M. \& Blumberg, D.G. 2003. The spectral reflectance properties of soil structural crusts in the $1.2-$ to $2.5-\mu \mathrm{m}$ spectral region. Soil Science Society of America Journal, 67, 289-299.

Bowers, S.A. \& Hanks, R.J. 1965. Reflection of radiant energy from soils. Soil Science, 100, $130-138$. 
Bronick, C.J. \& Lal, R. 2005. Soil structure and management: a review. Geoderma, 124, 322.

Chang, C.W., Laird, D.A., Mausbach, M.J. \& Hurburgh, C.R. 2001. Near-infrared reflectance spectroscopy-principal components regression analyses of soil properties. Soil Science Society of America Journal, 65, 480-490.

Clark, R.N. 1999. Spectroscopy of rocks and minerals, and principles of spectroscopy. In: Remote sensing for the earth sciences : manual of remote sensing (ed. Rencz, A.N.), pp. 3-58. John Wiley \& Sons, New York, NY.

Clark, R.N. \& Roush, T.L. 1984. Reflectance spectroscopy: Quantitative analysis techniques for remote sensing applications. Journal of Geophysical Research: Solid Earth, 89, 63296340.

Demattê, J.A.M., Sousa, A.A., Alves, M.C., Nanni, M.R., Fiorio, P.R. \& Campos, R.C. 2006. Determining soil water status and other soil characteristics by spectral proximal sensing. Geoderma, 135, 179-195.

Dexter, A.R. 2004. Soil physical quality - Part I. Theory, effects of soil texture, density, and organic matter, and effects on root growth. Geoderma, 120, 201-214.

Genot, V., Bock, L., Dardenne, P. \& Colinet, G. 2014. Use of near-infrared reflectance spectroscopy in soil analysis: A review. Biotechnologie, Agronomie, Société et Environnement, 18, 247-261.

Janik, L.J., Merry, R.H., Forrester, S.T., Lanyon, D.M. \& Rawson, A. 2007. Rapid prediction of soil water retention using mid infrared spectroscopy. Soil Science Society of America Journal, 71, 507-514.

Janik, L.J., Soriano-Disla, J.M., Forrester, S.T. \& McLaughlin, M.J. 2016. Moisture effects on diffuse reflection infrared spectra of contrasting minerals and soils: A mechanistic interpretation. Vibrational Spectroscopy, 86, 244-252. 
Kaleita, A.L., Tian, L.F. \& Hirschi, M.C. 2005. Relationship between soil moisture content and soil surface reflectance. American Society of Agricultural Engineers, 48, 1979-1986.

Kim, I., Pullanagari, R.R., Deurer, M., Singh, R., Huh, K.Y. \& Clothier, B.E. 2014. The use of visible and near-infrared spectroscopy for the analysis of soil water repellency. European Journal of Soil Science, 65, 360-368.

Knadel, M., Deng, F., Alinejadian, A., Wollesen de Jonge, L., Moldrup, P. \& Greve, M.H. 2014. The effects of moisture conditions - from wet to hyper dry—on visible near-infrared spectra of Danish reference soils. Soil Science Society of America Journal, 78, 422-433.

Lobell, D.B. \& Asner, G.P. 2002. Moisture effects on soil reflectance. Soil Science Society of America Journal, 66, 722-727.

McBratney, A.B., Minasny, B. \& Viscarra Rossel, R. 2006. Spectral soil analysis and inference systems: A powerful combination for solving the soil data crisis. Geoderma, 136, $272-278$.

Minasny, B. \& McBratney, A. 2006. A conditioned Latin hypercube method for sampling in the presence of ancillary information. Computers \& Geosciences, 32, 1378-1388.

Minasny, B. \& McBratney, A.B. 2018. Limited effect of organic matter on soil available water capacity. European Journal of Soil Science, 69, 39-47.

Minasny, B., McBratney, A.B., Tranter, G. \& Murphy, B.W. 2008. Using soil knowledge for the evaluation of mid-infrared diffuse reflectance spectroscopy for predicting soil physical and mechanical properties. European Journal of Soil Science, 59, 960-971.

Mouazen, A.M., Karoui, R., De Baerdemaeker, J. \& Ramon, H. 2006. Characterization of soil water content using measured visible and near infrared spectra. Soil Science Society of America Journal, 70, 1295-1302. 
Nolet, C., Poortinga, A., Roosjen, P., Bartholomeus, H. \& Ruessink, G. 2014. Measuring and modeling the effect of surface moisture on the spectral reflectance of coastal beach sand. Plos One, 9, e112151.

Pachepsky, Y. \& Rawls, W.J. 2003. Soil structure and pedotransfer functions. European Journal of Soil Science, 54, 443-451.

Patil, N.G. \& Singh, S.K. 2016. Pedotransfer functions for estimating soil hydraulic properties: A review. Pedosphere, 26, 417-430.

Rawls, W.J., Pachepsky, Y.A., Ritchie, J.C., Sobecki, T.M. \& Bloodworth, H. 2003. Effect of soil organic carbon on soil water retention. Geoderma, 116, 61-76.

Rodionov, A., Pätzold, S., Welp, G., Pallares, R.C., Damerow, L. \& Amelung, W. 2014. Sensing of soil organic carbon using visible and near-infrared spectroscopy at variable moisture and surface roughness. Soil Science Society of America Journal, 78, 949-957.

Romano, N. \& Palladino, M. 2002. Prediction of soil water retention using soil physical data and terrain attributes. Journal of Hydrology, 265, 56-75.

Sadeghi, M., Babaeian, E., Tuller, M. \& Jones, S.B. 2018. Particle size effects on soil reflectance explained by an analytical radiative transfer model. Remote Sensing of Environment, 210, 375-386.

Santra, P., Sahoo, R.N., Das, B.S., Samal, R.N., Pattanaik, A.K. \& Gupta, V.K. 2009. Estimation of soil hydraulic properties using proximal spectral reflectance in visible, nearinfrared, and shortwave-infrared (VIS-NIR-SWIR) region. Geoderma, 152, 338-349.

Saxton, K.E., Rawls, W.J., Romberger, J.S. \& Papendic, R.I. 1986. Estimating generalized soil-water characteristics from texture. Soil Science Society of America Journal, 50, 10311036. 
Stenberg, B. 2010. Effects of soil sample pretreatments and standardised rewetting as interacted with sand classes on Vis-NIR predictions of clay and soil organic carbon. Geoderma, 158, 15-22.

Stenberg, B., Viscarra Rossel, R.A., Mouazen, A.M. \& Wetterlind, J. 2010. Visible and near infrared spectroscopy in soil science. Advances in Agronomy, 107, 163-215.

Viscarra Rossel, R.A. \& Behrens, T. 2010. Using data mining to model and interpret soil diffuse reflectance spectra. Geoderma, 158, 46-54.

Whiting, M.L., Li, L. \& Ustin, S.L. 2004. Predicting water content using Gaussian model on soil spectra. Remote Sensing of Environment, 89, 535-552.

Zhu, Y., Weindorf, D.C., Chakraborty, S., Haggard, B., Johnson, S. \& Bakr, N. 2010. Characterizing surface soil water with field portable diffuse reflectance spectroscopy. Journal of Hydrology, 391, 133-140. 


\section{Figures Legends}

Figure 1 Location of the 13 soil sampling sites displayed on the geological map of Brittany (France).

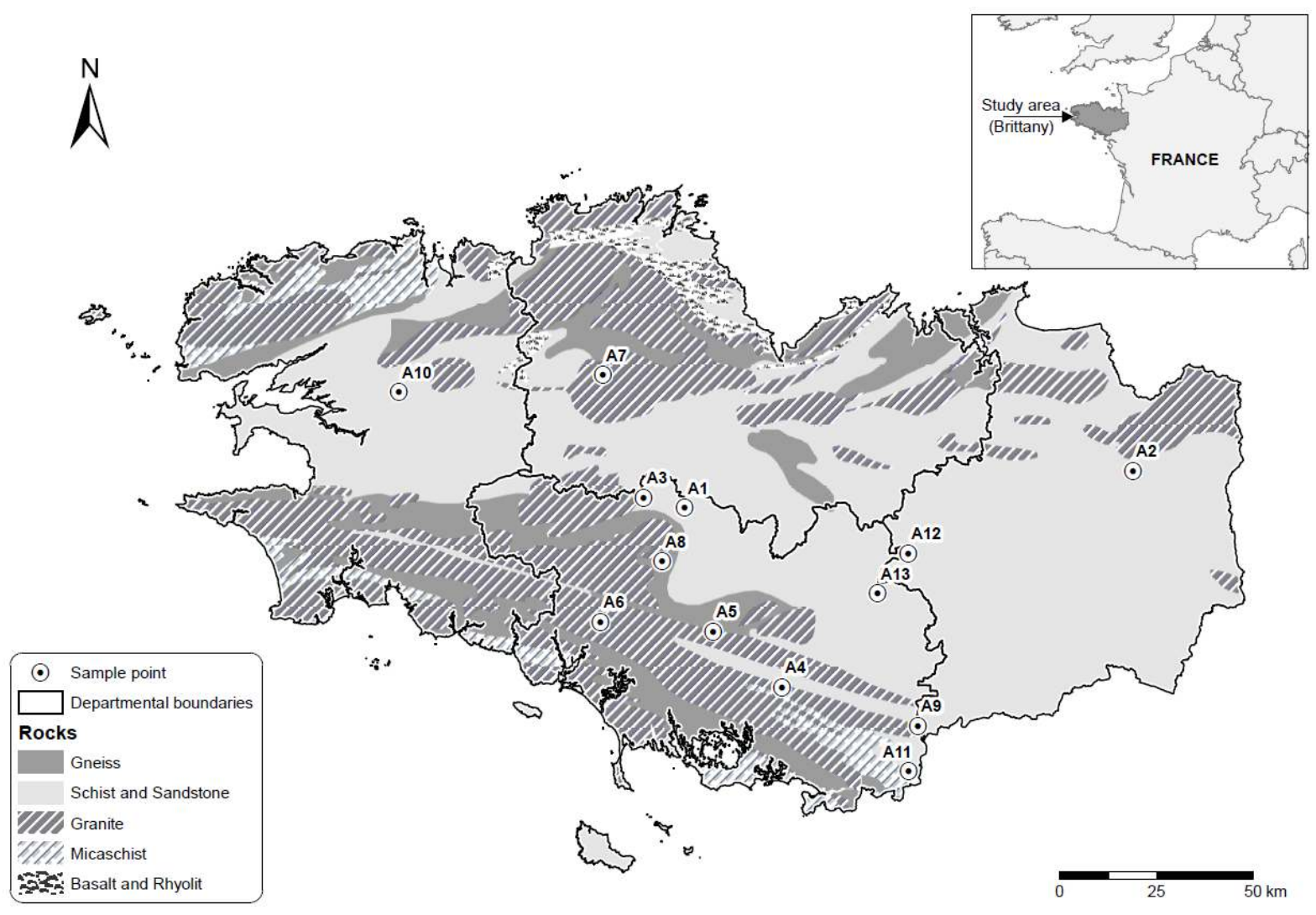


Figure 2 Texture classes of the 13 soil samples selected from a total of 59 A horizons according to the French textural triangle_GEPPA' soil texture classification system.

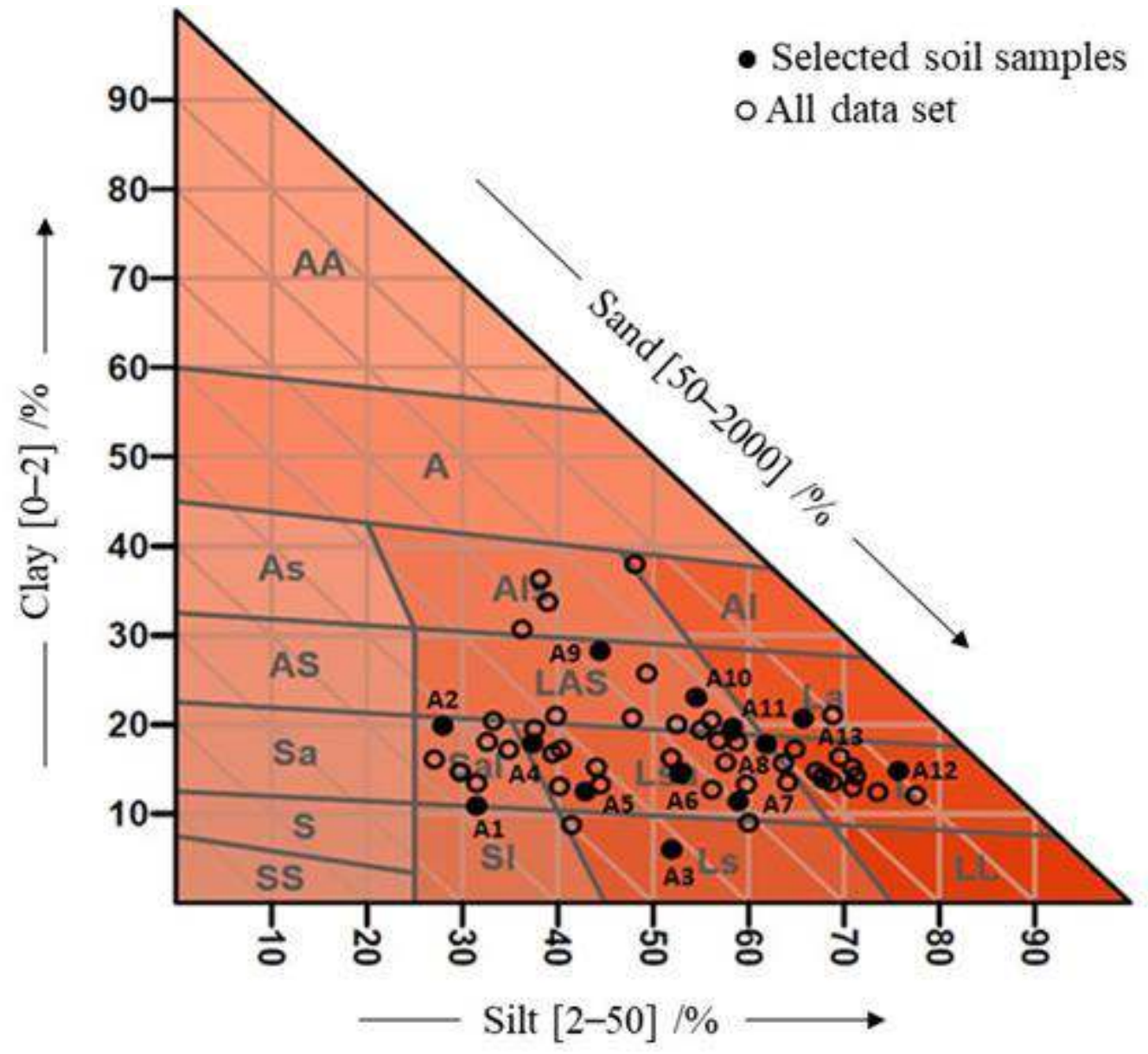


Figure 3 Average reflectance spectra of three soil samples with two different textural classes (LAS: A9 and A10, Ls: A3) and with two different SOC contents: large (A10: $50.85 \mathrm{~g} \mathrm{~kg}^{-1}$ and A3: $48.65 \mathrm{~g} \mathrm{~kg}^{-1}$ ) and small (A9: $19.68 \mathrm{~g} \mathrm{~kg}^{-1}$ ).

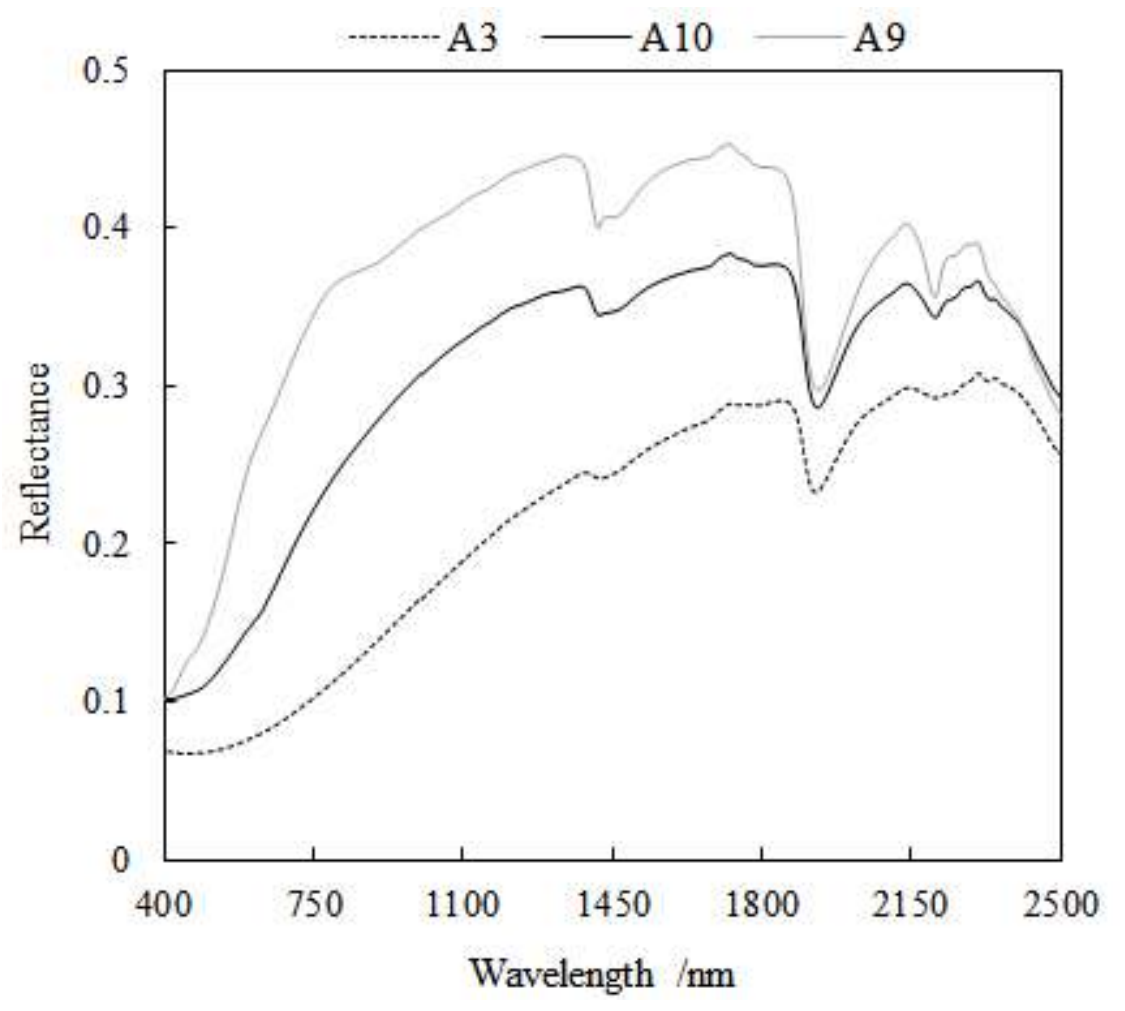


Figure 4 Spectral reflectance soil sample A11 according to pressure heads: (a) reflectance spectra, (b) continuum removal and (c) absorption band near $1920 \mathrm{~nm}$.
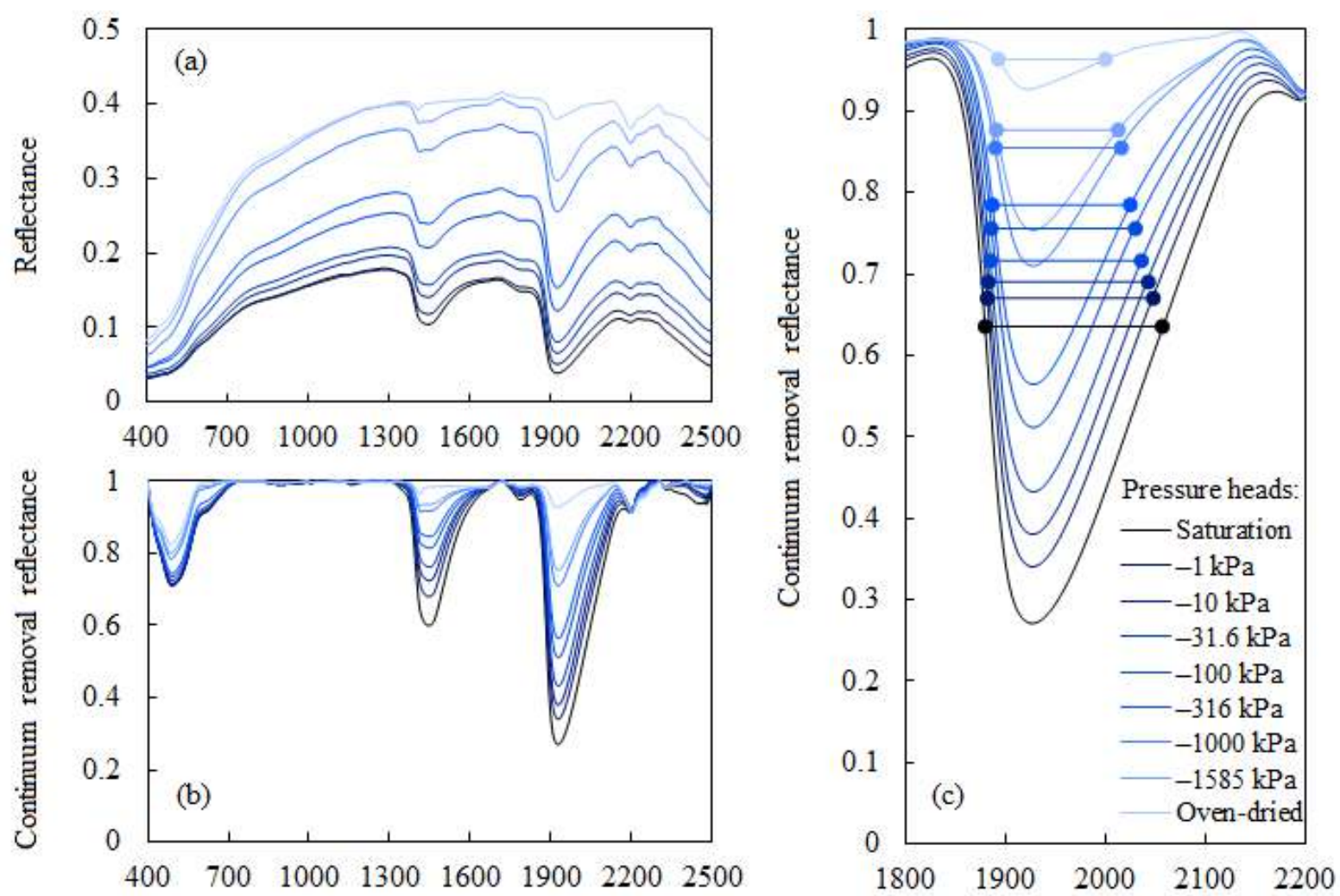

Wavelength /nm

Wavelength /nm 


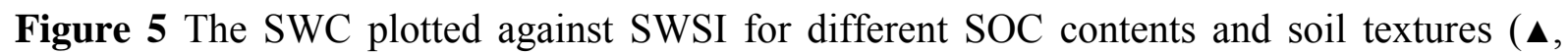
coarse-textured soil with large SOC content; $\Delta$, coarse-textured soil with small SOC content; $\diamond$, medium-textured soil with large SOC content; $\diamond$, medium-textured soil with small SOC content; •, fine-textured soil with large SOC content and ○, fine-textured soil with small SOC content).

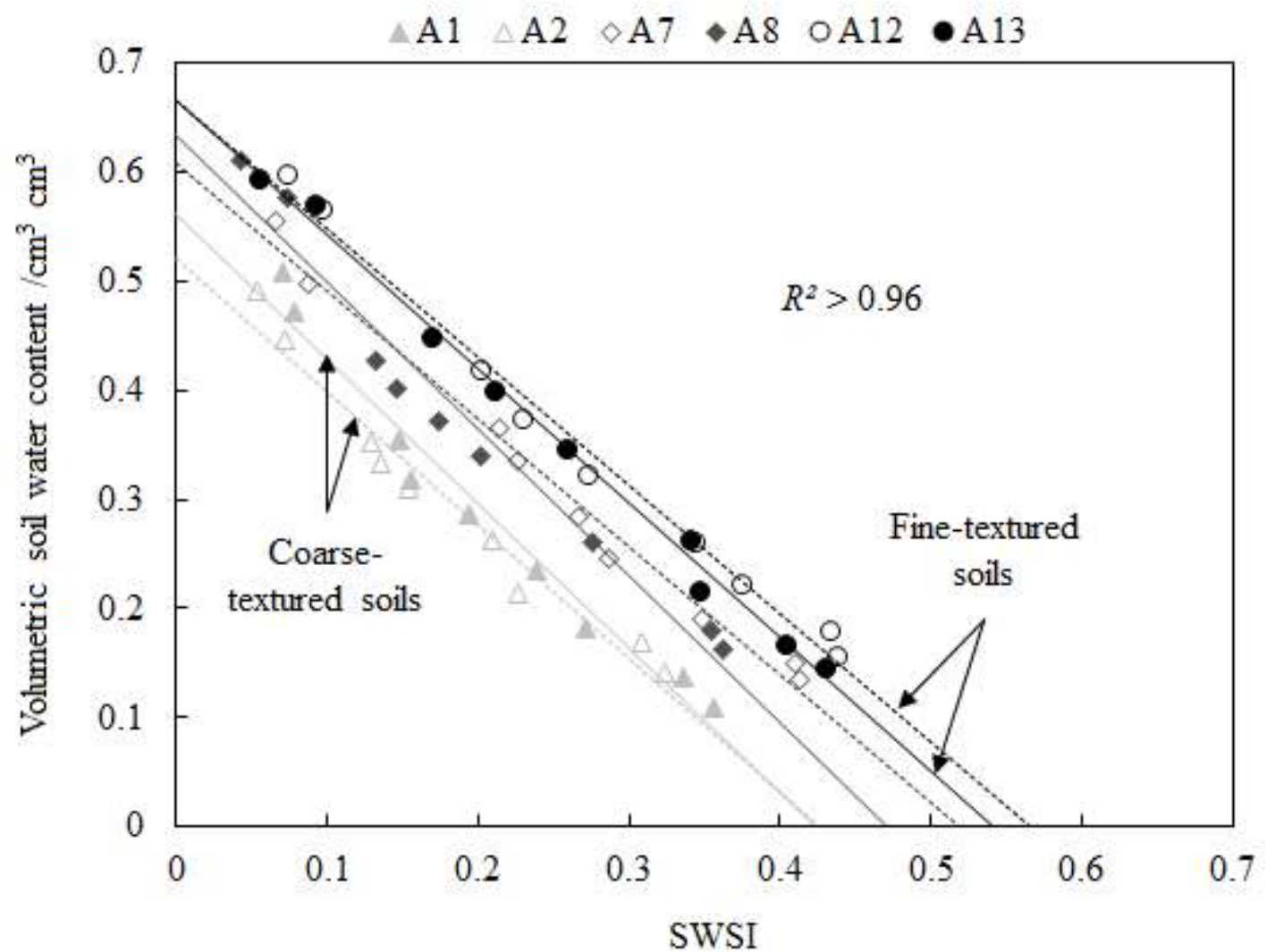


Figure 6 Projecting groups of soil samples according to their texture and SOC content in the plane of the Intercept and AvS. Coarse-textured groups G1, G3 and G5 and fine-textured groups G2, G4 and G6.

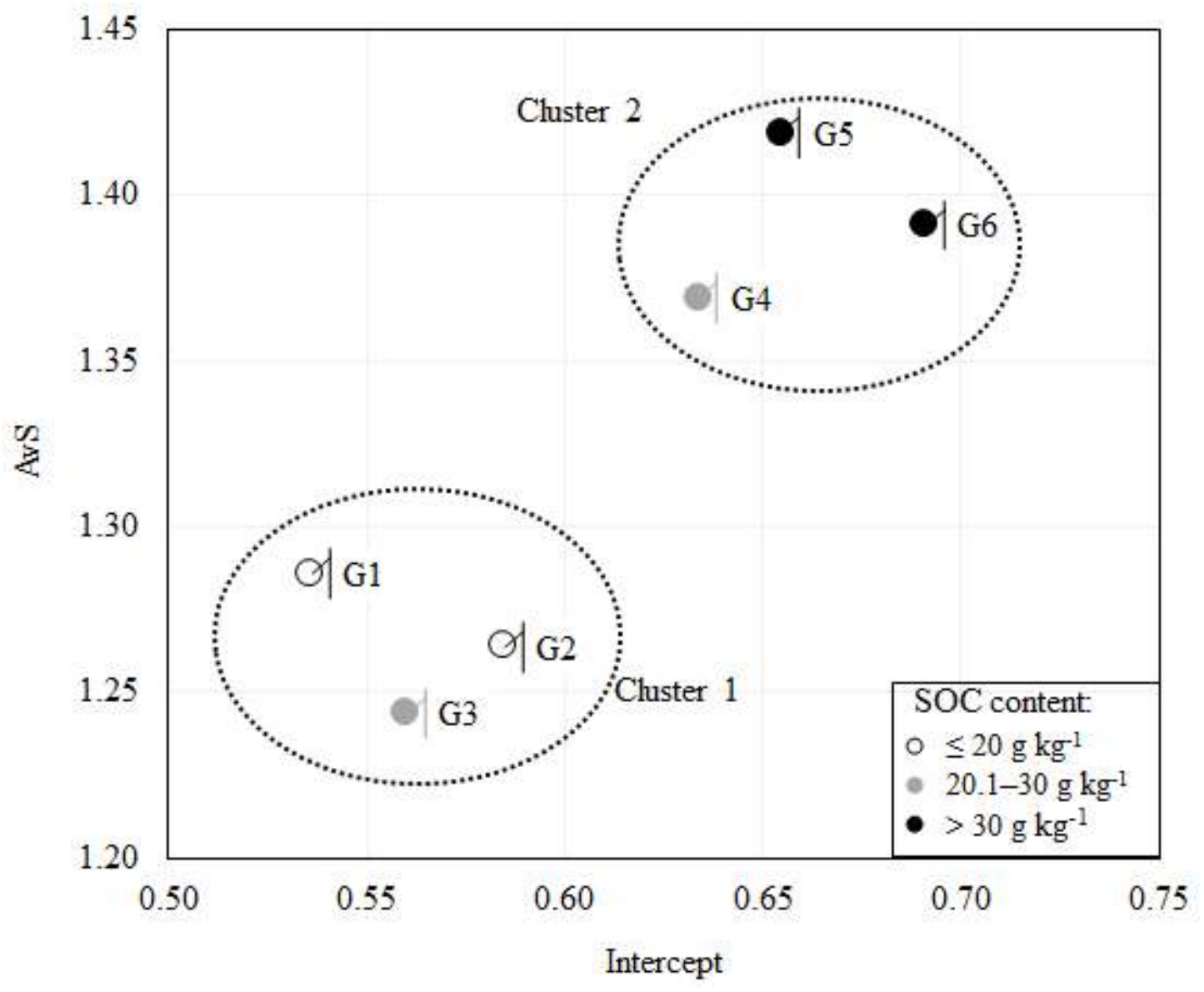




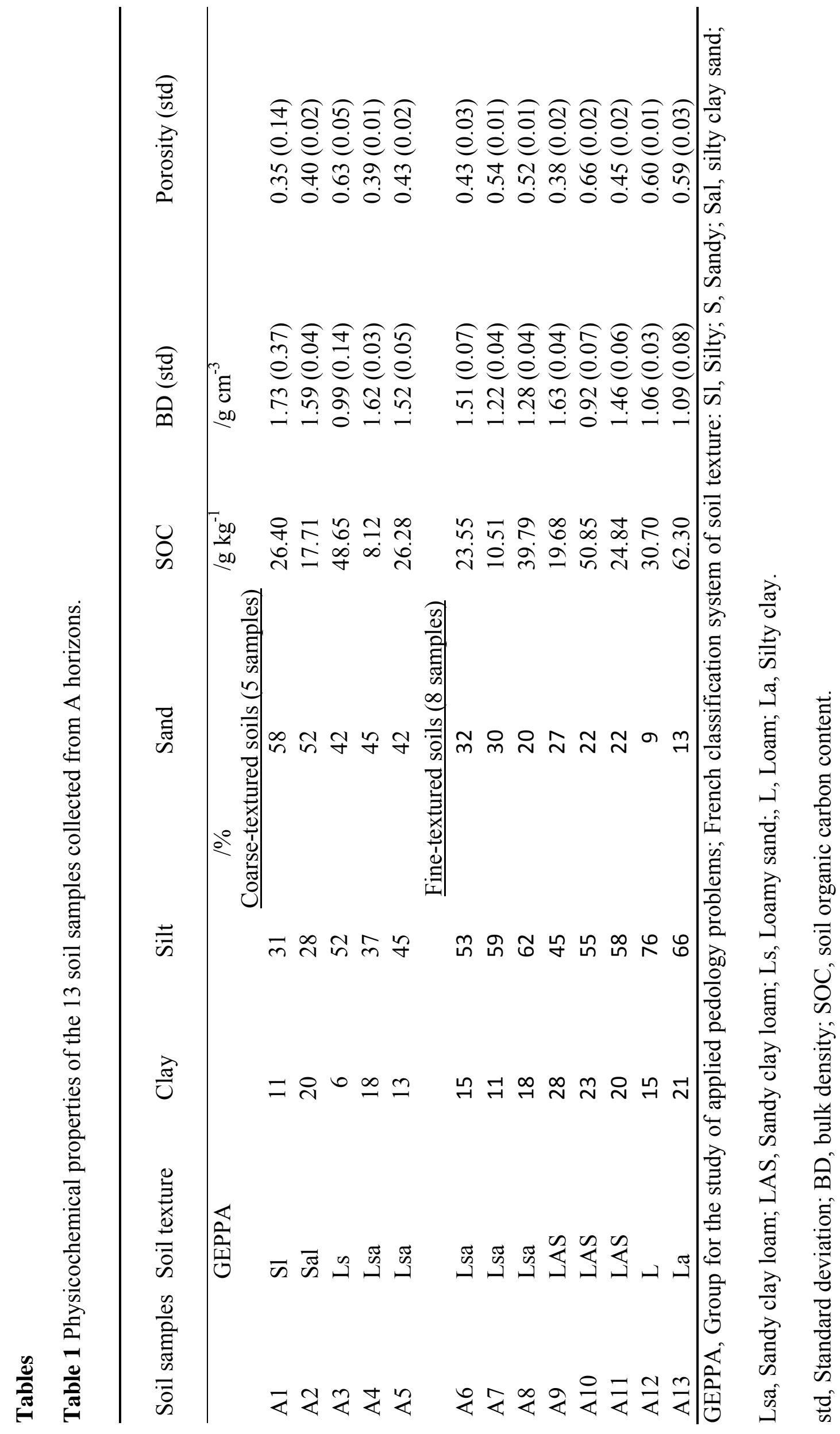




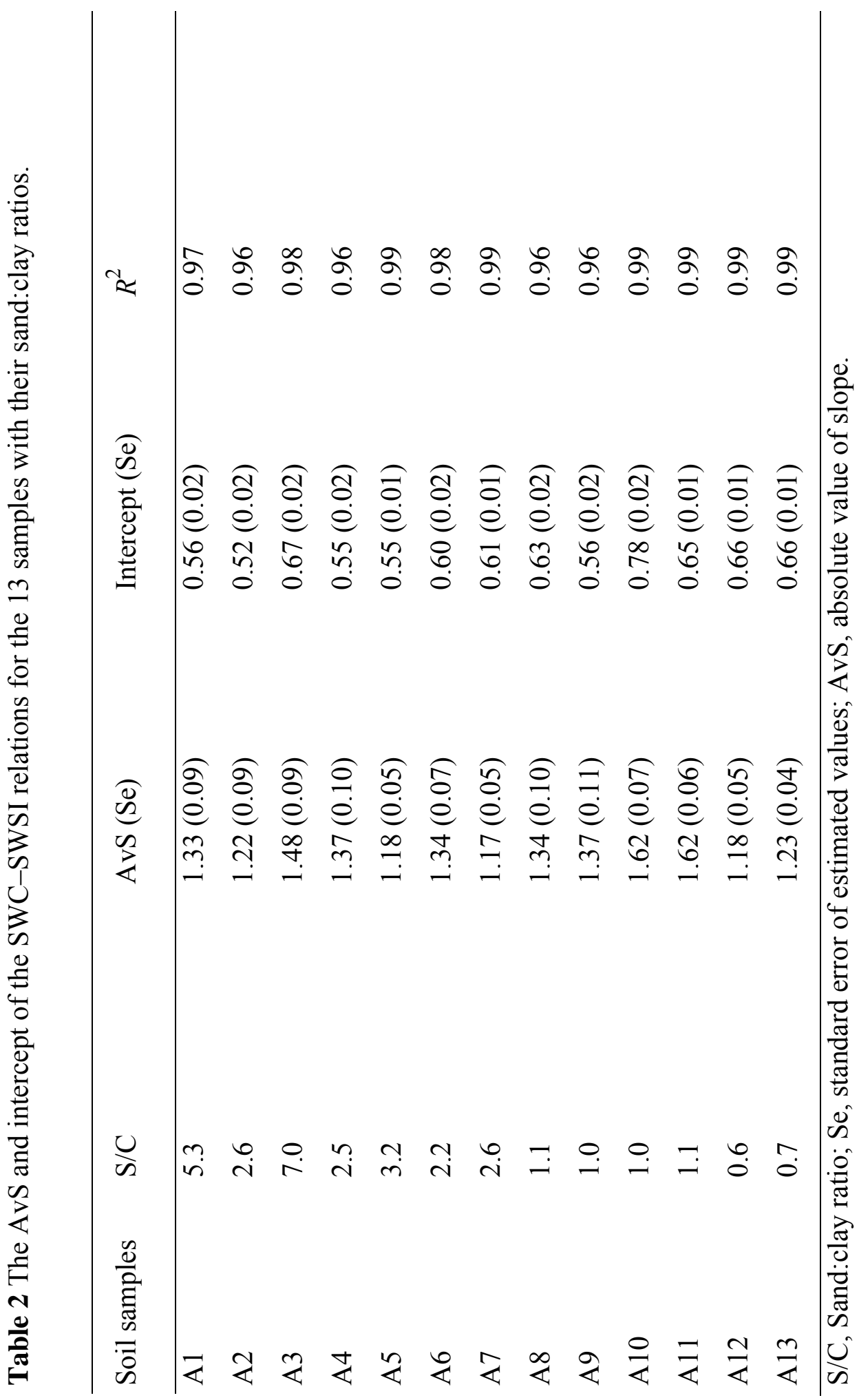




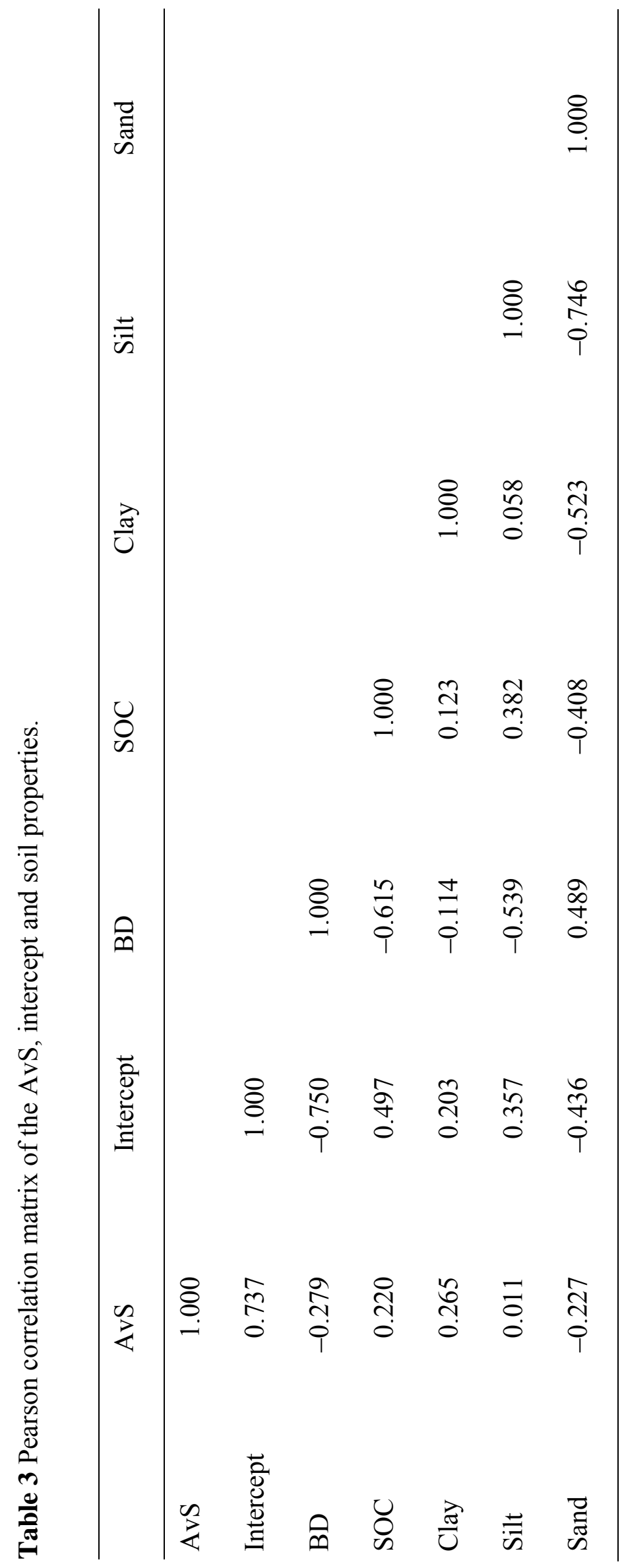




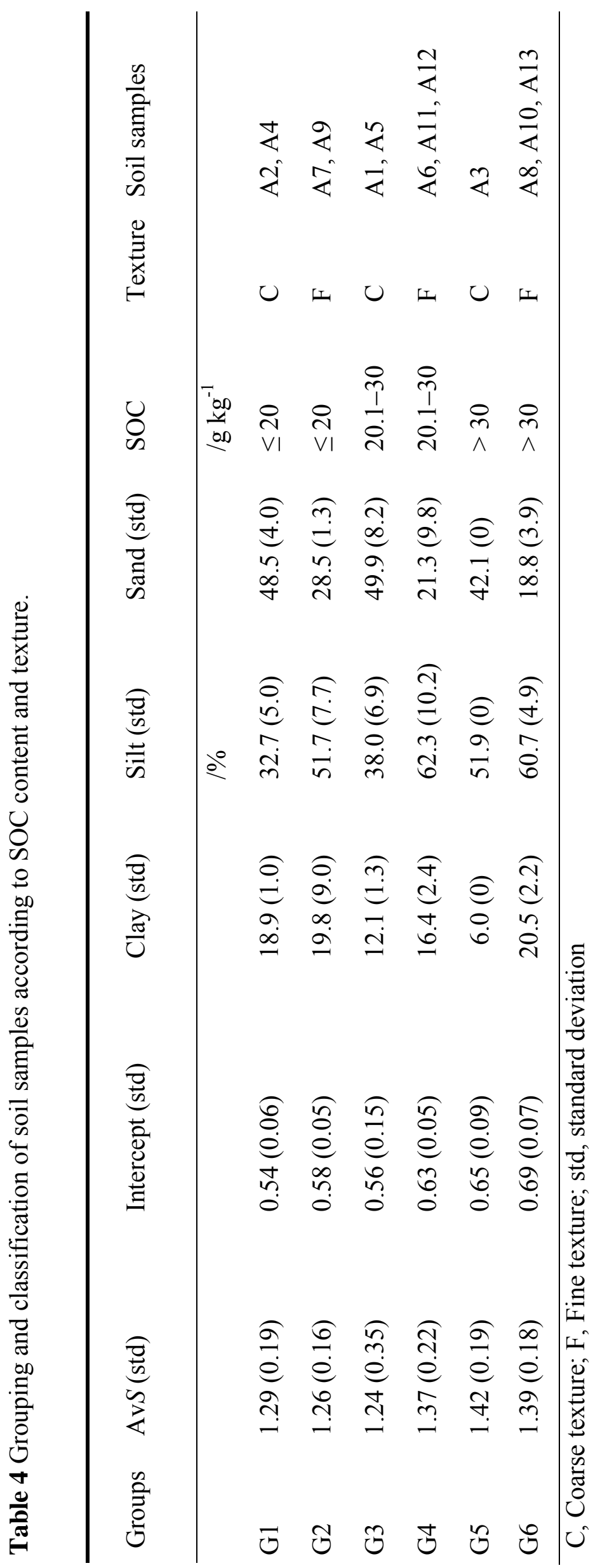




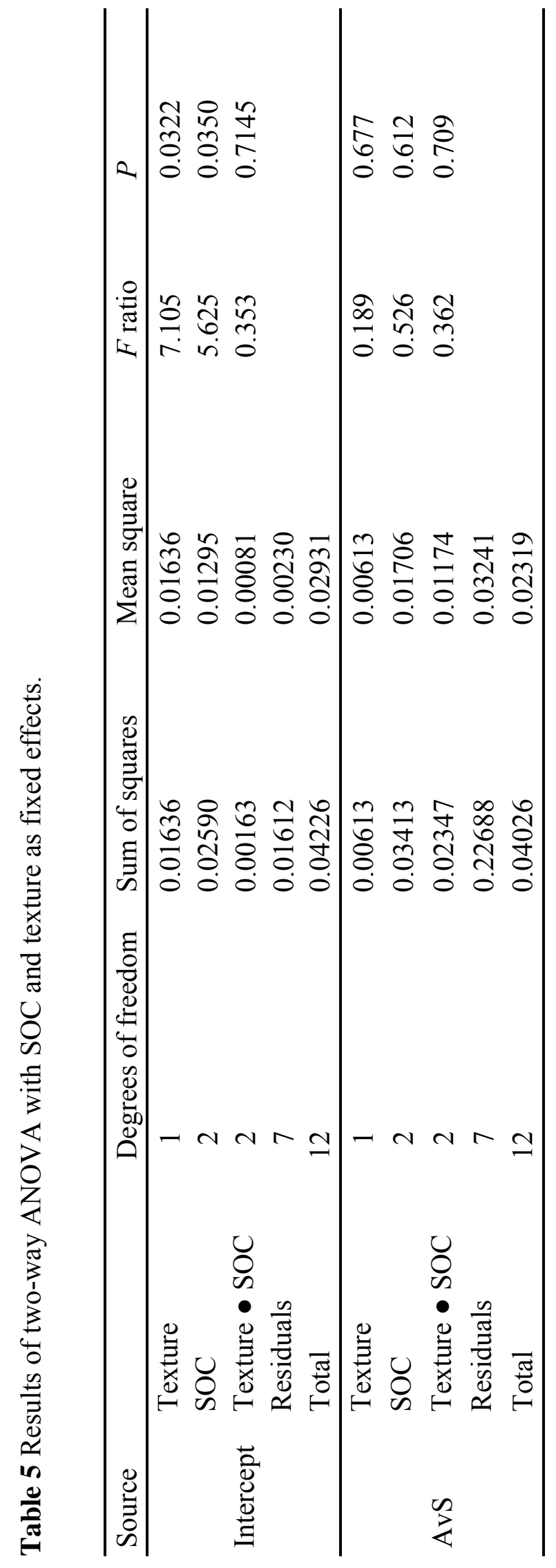

